\title{
Do evolutionary debunking arguments rest on a mistake about evolutionary explanations?
}

\section{Abstract:}

Many moral philosophers accept the Debunking Thesis, according to which facts about natural selection provide debunking explanations for certain of our moral beliefs. I argue that philosophers who accept the Debunking Thesis beg important questions in the philosophy of biology. They assume that past selection can explain why you or I hold certain of the moral beliefs we do. A position advanced by many prominent philosophers of biology implies this assumption is false. According to the Negative View, natural selection cannot explain the traits of individuals. Hence, facts about past selection cannot provide debunking explanations for any of our moral beliefs. The aim of this paper is to explore the conflict between the Debunking Thesis and the Negative View.

\section{Introduction}

Evidence suggests that human morality has evolved under natural selection. However, our best understanding of the evolutionary process indicates that there has been no selection for true moral beliefs. Many philosophers feel that evolutionary explanations in moral psychology are therefore debunking. ${ }^{1}$ More exactly, they accept what I shall call the Debunking Thesis: that facts about natural selection provide debunking explanations for certain of our moral beliefs.

I argue that philosophers who accept the Debunking Thesis beg important questions in the philosophy of biology. In particular, they assume that past selection may explain why

\footnotetext{
${ }^{1}$ Crisp (2006), de Lazari-Radek \& Singer (2012), Huemer (2008), Joyce (2000, 2001, 2006), Parfit (2011), Rosenberg (2011), Ruse (1986), Singer (1981, 2005, 2006). Kahane (2011) and Street (2006, 2008, 2011) hedge this conclusion: natural selection explanations are debunking iff we assume some form of meta-ethical realism.
} 
you or I hold certain of the moral beliefs that we do. A position accepted by many prominent philosophers of biology implies that this assumption is false: although natural selection explains many important evolutionary trends, it cannot explain the traits of individuals; instead, the traits of individuals are to be explained by inheritance, development, and other proximate factors. ${ }^{2}$ Following tradition, I call this the Negative View. The Negative View entails that facts about past selection cannot form part of discrediting explanations for any of my moral beliefs, nor those of any other human being.

The aim of this paper is to explore the conflict between the Debunking Thesis and the Negative View. Section 2 will explain what those who accept the Debunking Thesis believe, and why they believe it. Section 3 will offer a similar treatment of the Negative View. I will then consider how those who accept the Debunking Thesis might respond to the conflict between the Negative View and the Debunking Thesis. I examine whether they might do well to look for counterexamples to the Negative View (section 4) or to recast their arguments so as to beg no questions in the philosophy of biology (section 5). I argue that either approach faces significant problems. Finally, in section 6, I suggest that a better response may be to retain our commitment to the idea that evolutionary considerations can debunk our moral beliefs, but give up the claim that these considerations have to do with natural selection. Instead, I suggest, evolutionary debunking arguments would do well to emphasize the explanatory significance of phylogeny.

\section{Evolutionary debunking arguments in ethics}

Many contemporary philosophers believe, as stated, that our moral beliefs can be debunked by the provision of information about the selection pressures affecting the evolution of

\footnotetext{
${ }^{2}$ Pust (2001, 2004), Sober (1984, 1995), Walsh (1998), Walsh, Lewens, \& Ariew (2002). In some respect, this claim is also endorsed by Lewens (2001) and Matthen (1999, 2002, 2004); see sections 3 and 4 for further discussion.
} 
morality. In assessing this claim, the first thing we need to do is become a little clearer on what it means. We can start by asking what it is for a belief to be debunked.

It is common to understand the notion of debunking using the idiom of defeat, introduced by John Pollock (1970, 1986). Thus, I will assume that a belief is debunked by virtue of being subject to a defeater, where a defeater is a condition that provides a prima facie reason to withhold belief from some proposition that one would otherwise have been justified in believing. For example, if Expert 1 tells me $\ulcorner p\urcorner$, but later Expert 2 tells me $\ulcorner\neg p\urcorner$, the latter constitutes a defeater. The testimony of the second expert cancels my preexisting justification for believing the first expert's testimony by providing an equally strong reason to believe to the contrary. A defeater of this kind is called rebutting. If Expert 1 tells me $\ulcorner p\urcorner$, but I then learn that her utterance was the result of momentary psychosis, this also constitutes a defeater. Learning that her utterance is due to mental illness cancels my pre-existing justification for trusting Expert 1's testimony by providing evidence that the causal factors relevant to my acquisition of the belief and/or the evidence on which it is based are in some sense discrediting. A defeater of this kind is called undercutting.

Philosophers agree that if evolutionary considerations provide defeaters for our moral beliefs, these are undercutting defeaters, rather than rebutting defeaters. ${ }^{3}$ Evolutionary considerations do not speak directly to the truth or falsity of our moral beliefs. Instead, they are supposed to indicate that the causal factors relevant to the acquisition of certain of our moral beliefs are discrediting.

The proponents of evolutionary debunking arguments rely on the premise that certain elements of our moral psychology are the product of natural selection. They vary in their assumptions about which elements of our moral psychology represent adaptations. Rarely do they assume that particular moral beliefs with determinate contents have been the object of selection. For example, Richard Joyce (2001, 2006) assumes that selection explains

\footnotetext{
${ }^{3}$ See, e.g., Joyce (2006), Kahane (2011).
} 
why we are disposed to apply moral concepts to features of the world. According to Joyce, "Natural selection has provided us with a tendency to invest the world with values" (2001: 136). However, Joyce remains agnostic as to what extent, if any, selection has played a role in determining which features of the world are classified with which moral concepts. By contrast, Sharon Street $(2006,2008,2011)$ assumes that natural selection has played an important role in determining the content of our ethical beliefs, albeit indirectly. Street believes that selection accounts for certain basic evaluative tendencies that we have inherited; these primitive evaluative dispositions, in turn, bias our ethical beliefs in certain directions.

The role of natural selection in the evolution of morality is supposed to be discrediting because it appears that there has been no selection for psychological structures that would incline us to adopt true moral beliefs. In other words, the advantages conferred by those elements of our moral psychology that have evolved by selection are independent of any assumptions regarding the truth or falsity of any corresponding moral beliefs. Street (2008) illustrates the general principle as follows: "the best explanation of why we tend to value our survival is not that it's independently true that our survival is valuable ... but rather, much more simply, that creatures who valued their survival tended to do what promoted it, and therefore left more descendants." (209) To put the point in more anthropomorphic terms: in designing the human moral sense, natural selection didn't aim for truth or reliability.

Philosophers who accept the Debunking Thesis are not agreed as to exactly which epistemic principles allow us to conclude that the failure of natural selection to select for true moral beliefs is defeating. Some believe that this information can be used in combination with Ockham's Razor to undermine belief in moral facts. ${ }^{4}$ Others suppose that this information can be used to show that we would hold certain of our moral beliefs even if

\footnotetext{
${ }^{4}$ Joyce (2006), Ruse (1986). Cf. Gibbard (1990).
} 
they were false, and this provides a reason for us to abandon these beliefs. ${ }^{5}$ Street (2006, 2008, 2011) appeals to the suggestion that it would have to have been an extraordinary coincidence if the basic evaluative tendencies favoured by selection tend in the direction of the objective truth. ${ }^{6}$

There are other sources of diversity. Philosophers who accept the Debunking Thesis disagree about the extent of the required revisions in our moral outlook: some believe that only a proper subset of our moral beliefs must be revised; ${ }^{7}$ some believe that everything must go. ${ }^{8}$ They may also disagree about whether the truth of the Debunking Thesis hinges on particular meta-ethical assumptions. Some believe that the Debunking Thesis is true iff meta-ethical objectivism is the best account of the truth-conditions of our moral beliefs; ${ }^{9}$ others deny this. ${ }^{10}$

Underlying this diversity is the common belief that natural selection explains certain moral beliefs that we hold, and that it does so in a discrediting fashion. Those who accept the Debunking Thesis must assume that natural selection is in principle able to explain why you or I have the concept of moral obligation, or why we have a disposition to value our survival, or something along those lines. Otherwise facts about natural selection could not give rise to undercutting defeaters for our moral beliefs. This implies that natural selection explains the traits of individuals. This assumption may appear innocent. It may be thought to be a cornerstone of the Darwinian view of evolution. In fact, it is subject to powerful objections.

\footnotetext{
${ }^{5}$ Joyce (2001), Ruse (1986), Parfit (2011). Cf. Nozick (1981, 342-348).

${ }^{6}$ See also Huemer (2008), Rosenberg (2011). For further discussion of Street's view, see section 6.

${ }^{7}$ Crisp (2006), Huemer (2008), Singer (2005), Parfit (2011).

${ }^{8}$ Joyce (2006), Kahane (2011), Rosenberg (2011), Ruse (1986).

${ }^{9}$ Kahane (2011), Street (2006).

10 Joyce (forthcoming).
} 


\section{The Negative View}

Like the claim that our moral beliefs can be debunked by information about the evolution of morality, the claim that natural selection does not explain the traits of individuals requires some initial clarification. In particular, it is important to be clear on what it does not imply. This will help to show why the Negative View does not conflict with the Darwinian view of nature.

Firstly, the Negative View leaves open and is often asserted in conjunction with the claim that selection explains the frequencies with which traits occur in populations. An analogy proposed to Elliot Sober (1984) helps to clarify the point. Suppose that no child is admitted to a certain room unless they can read at a third grade level. Various children are examined: some are accepted, others are rejected. The selection procedure will explain why all of the children in the room read at a third grade level. However, it will not explain, of any particular child in the room, why she has this level of reading proficiency. Similarly, according to the Negative View, natural selection does not explain why any particular individual within a given population exhibits some trait, though it often explains why some percentage of the population exhibits the trait in question.

Secondly, the Negative View is distinct from the view that natural selection cannot explain the origin of traits. ${ }^{11}$ Some have thought that traits originate by mutation and are then merely sieved by selection; traits never arise because of selection. ${ }^{12}$ The Negative View does not commit us to this picture. The picture is not plausible, in any case, when we consider traits such as echolocation or bipedal motion. Complex adaptations such as these depend on many subtle changes in the genome: these traits could not have arisen except through the gradual retention and spread of innumerable minor modifications arising

\footnotetext{
11 These positions are sometimes run together: e.g., by Martinez \& Moya (2011) and Neander (1988, 1995a, 1995b). Forber (2005) is careful to distinguish these questions, as are Razeto-Barry \& Frick (2011).

${ }^{12}$ See Cummins (1975).
} 
independently of one another. Their retention and spread must be explained by selection, and thus selection explains the origin of traits such as these. ${ }^{13}$ The Negative View is compatible with this. The Negative View allows that natural selection explains why there exist organisms that have some trait $T$, as opposed to there being no organisms that exhibit this trait. The Negative View merely denies that there exists any particular organism such that past selection explains why it has $T$, as opposed to lacking $T$.

Once the Negative View is properly clarified in this way, it appears much less surprising or revisionary. It cannot easily be dismissed. We can add further plausibility to the Negative View by thinking critically about the suggestion that what you or I value may be explained by facts about past selection pressures. Street (2011) says: "we probably value many of the things we do ... because valuing such things tended to enhance reproductive success in the environment of our ancestors." (12) As we'll now see, it is prima facie difficult to understand how this could be the case. ${ }^{14}$

The suggestion we are to consider is that what you or I value depends in some way on the rate at which ancestral hominids reproduced. Imagine, then, two ancestral hominids, $A$ and $B$, who exist at some point in the Pleistocene epoch. $A$ is my ancestor. Like me, she has an innate predisposition to form the belief that she must reciprocate benefits; I have inherited this predisposition from her. $B$ lacks this predisposition. Due to certain conditions that determine the fitness-consequences associated with the trait of reciprocity, $A$ is fitter than $B$, and so $A$ contributes more offspring to the subsequent generation. These offspring, we'll assume, inherit her predisposition to believe that benefits should be reciprocated. In what way could my present disposition to adopt this belief depend on the greater reproductive success of $A$ in this context?

\footnotetext{
${ }^{13}$ See Dawkins (1986), Forber (2005), Neander (1995a).

${ }^{14}$ My reasoning in the following draws on a similar discussion in Sober (1995).
} 
It is easy to see how $A$ 's reproductive success may explain why the belief that benefits should be reciprocated increases in frequency over time. It is also easy to see that if $A$ had had fewer children, then I might never have come to exist, because the lineage which leads from $A$ to me would not have occurred. This shows that $A$ 's reproductive success may explain why I exist, as opposed to being non-existent. The relevant explanandum, however, is not my existence, but my having a certain innate predisposition to believe that benefits should be reciprocated. I might conceivably have existed without this disposition. It remains unclear how this state of affairs might have come about as a result of $A$ having greater or fewer children. So it is unclear in what sense my possession of this trait depends on $A$ 's reproductive success. ${ }^{15}$

Similar points apply with respect to the reproductive success of $B . B$ might have had more children or fewer. In so doing, she might have altered the frequency with which (un)belief in reciprocity occurs in subsequent generations. However, it is prima facie obscure how she might thereby have produced a world in which I exist without my innate predisposition to value reciprocity. How could the existence of a greater or lesser number of her descendants have altered me in this way?

One possibility, suggested by Karen Neander (1988) and developed in greater detail by Mohan Matthen (1999), is that selection might determine an organism's traits by affecting the frequency with which certain alleles occur in the ancestral gene pool from which the organism must inherit its genotype. Because the organism's genome must be drawn from this pool, one might think that the relative frequency with which a certain allele

\footnotetext{
${ }^{15}$ Someone might think that since $o$ 's existence is necessary for $o$ to have $T$, explaining $o$ 's existence partially explains why $o$ has $T$, and so selection for $T$ can explain why $o$ has $T$ if it can explain why $o$ exists. But in that case, whenever natural selection explains an organism's existence, it would explain all of its properties. Thus, in our example, selection for the trait of reciprocity would explain why I wear blue jeans or once owned a bike with a red frame. This, I take it, is absurd.
} 
occurs determines the probability of inheriting it: the rarer the gene, the lower the probability. Thus, if a certain allele is driven to fixation in prior generations, this may explain why I exhibit a certain corresponding trait: by driving individuals carrying alternative alleles from the population, selection ensured that I would inherit this allele, rather than its extinct competitors. Stated differently: if selection against alternative alleles had not been as strong, one of my ancestors might have been a carrier of some alternative allele, and consequently my genotype and phenotype might have been different.

Whilst superficially plausible, it is well known that this line of reasoning runs into problems because it contradicts Origins Essentialism, as defended by Kripke (1980). ${ }^{16}$ The reasoning in the previous paragraph assumed that I might have had a different genotype if one of my ancestors had mated instead with an individual carrying an allele that was in actuality rendered extinct by selection. According to Origins Essentialism, each of us could not have been born to different parents. It is equally true that our parents could not have been born to different parents, and so forth. On this view, my ancestry constitutes an essential property of me. It is therefore false that I might have had a different genotype had one of my ancestors mated with a someone else - someone carrying an allele that was in actuality rendered extinct by selection. Had that occurred, I would not exist, because the particular lineage of couplings from which I originate would not have existed.

Joel Pust (2001, 2004) has seized on this point to argue that Origins Essentialism suffices to establish the Negative View. Selection is limited to determining the rate at which individuals of certain types contribute descendants to successive generations. Selection determines, in effect, which lineages exist and which do not. According to Origins Essentialism, my lineage is an essential property of me. Thus, if natural selection is limited to determining which lineages exist, the only thing about me that would appear to be explained by past selection is my existence.

${ }^{16}$ See Matthen (1999), Pust (2001). 
Matthen (1999, 2002, 2003), in turn, has argued that Origins Essentialism is too metaphysical to be of relevance to our understanding of contemporary biology. Matthen claims that explanations in population genetics should be interpreted as referring to individuals understood merely as receptacles for genes. Genetic receptacles of this kind, he suggests, should be understood such that they could have existed with a different genotype if certain prior individuals had mated differently; the assumption that they must be individuated in terms of their ancestry goes beyond anything required by the theory of evolution. Thus, to the extent that Origins Essentialism is true of a certain class of individuals, Matthen suggests, these simply fall outside the ontology of population genetics. Objections have been lodged against this interpretation by Pust (2004) and by Tim Lewens (2001). However, for our purposes Matthen's view is strictly irrelevant, so long as we assume that Origins Essentialism applies to you and me. Our interest is in whether facts about past selection explain why you or I hold certain moral beliefs, and how we should react to this. The explanatory significance of natural selection for the traits of a different class of entities is quite irrelevant.

This completes my overview of the case for the Negative View. It is far from being the final word. ${ }^{17}$ What I hope to have shown is that the Negative View is not as implausible as it might first have seemed: it has a number of considerations in its favour. Thus, any conflict between the Debunking Thesis and the Negative View deserves to be taken seriously.

The existence of such a conflict should be clear enough. The Debunking Thesis states that facts about the selection pressures affecting the evolution of morality provide discrediting explanations for certain of our moral beliefs. According to the Negative View, past selection pressures do not explain our moral beliefs. If the Negative View is true, the

\footnotetext{
${ }^{17}$ Nanay $(2005,2010)$ provides a recent argument against the Negative View. For replies, see Helgeson (2013), Stegmann (2010a, 2010b). Birch (2012) argues that the Negative View is ruled out if we adopt a criterion of explanatory relevance proposed by Strevens (2008: 174-177).
} 
explanation that we should accept for why you or I believe what we do about right and wrong should be same whether we suppose that beliefs of this kind were selectively advantageous because they were true or for some other reason. Since adopting the view that there was no selection for true moral beliefs makes no difference to the explanation of our moral beliefs, it is mysterious how it could make any difference to our reasons for revising these beliefs, assuming that any such reasons would have to come in the form of evidence about their discreditable causal origins. The causal origins should be thought the same whatever we believe about the nature of selection.

Of course, the Negative View allows that past selection may explain why certain ethical beliefs are prevalent in our species. Thus, if nearly everyone values reciprocity or attaches more importance to the welfare of their own children, this may well be explicable in terms of natural selection. In this sense, truth-indifferent selection pressures may be said to explain why we as a species have the moral beliefs we do, even if they do not explain why we as individuals have such beliefs.

The former might not immediately seem a less disturbing thought than the latter. However, a little reflection shows that the knowledge that one belongs to a group in which the prevalence of some belief is explained by truth-indifferent selection pressures doesn't challenge the justification of one's belief in the same way as discovering that such arbitrary factors explain why one holds the belief in question. This can be seen by considering a case described by Roger White (2010). ${ }^{18}$

Suppose you go to a party at Adam's house. At the door, Adam asks you whether Napoleon invaded Egypt. Drawing on your memory of French history, you answer, 'Yes,' and head on in to enjoy the party. Later, you discover something shocking. Having recently become insane, Adam decided that he would ask each person at the door whether Napoleon invaded Egypt and depending on how they answered, he would either let them join the

\footnotetext{
${ }^{18}$ I have modified the details of this case slightly.
} 
party or kill them silently on the spot. Furthermore, he decided which answer received which response without any concern for the truth of the matter: he flipped a coin to determine whether a 'Yes' or a 'No' meant life or death. Worst of all, Adam murdered a number of would-be party-goers who did not believe that Napoleon invaded Egypt.

This is obviously a very disturbing discovery, but on its face nothing in the story challenges your belief that Napoleon invaded Egypt. As a party-guest, you belong to a group in which the prevalence of the belief that Napoleon invaded Egypt is explained by the operation of a truth-indifferent selection pressure: Adam's homicidal policy explains why the party-guests as a group believe that Napoleon invaded Egypt. However, since his actions do not explain why you believe this about Napoleon, there seems to be no challenge to your belief. Similarly, the capacity of natural selection to explain why human beings as a group hold certain moral beliefs would not appear to challenge the justification of the moral beliefs that we as individuals hold, presuming the Negative View is true.

Thus, if selection does not explain the traits of individuals, it appears mistaken to give up any of our moral beliefs on the assumption that facts about past selection pressures constitute or imply the presence of undercutting defeaters for those beliefs. Given that the Negative View is prima facie plausible, how might proponents of the Debunking Thesis address this conflict?

\section{Denying the Negative View}

The most obvious response would, of course, be to reject the Negative View. Reasons would have to be found for doing so, but reasons of that kind are to be had. Whereas I have rehearsed a number of considerations that I believe confer significant plausibility on the Negative View, I believe that it is only very nearly true: there are certain clear counterexamples. However, these counterexamples to the Negative View ultimately provide little comfort to proponents of the Debunking Thesis. 
As Tim Lewens (2001) has noted, there are some traits whose acquisition can be explained by prior selection for organisms possessing those traits: namely, traits whose development depends on the prior frequency with which they occur within a population. If an organism, $o$, acquires a certain trait, $T$, in the course of ordinary development only if $n \%$ of the population already exhibit $T$, selection for $T$ could explain why $o$ has $T$ by explaining why more than $n \%$ of the population exhibit $T$, as everyone grants that it may. In this way, selection for a trait may explain why certain individuals exhibit that trait. Thus, the Negative View is false in some cases involving traits whose development is sensitive to their prior distribution in the population. ${ }^{19}$

Is this any comfort to those who hold the Debunking Thesis? Well, it means, of course, that the Debunking Thesis may be true for moral beliefs whose adoption is contingent on their prior distribution within the population. The most obvious cases of this kind would be beliefs that we adopt simply because we follow the majority. The least plausible candidates, I think, would be moral beliefs with an innate basis. Innate behaviours, I assume, are not learned and their ontogeny is canalized against environmental variability: within normal parameters, they develop come what may. ${ }^{20}$ Of all traits, innate characteristics are thus least likely to depend for their ontogeny on particular features of the developmental environment, such as those we have been discussing. Paradoxically, it is when a trait is innate that its possession by some particular organism is least likely to be explained by selection.

The view that evolutionary considerations may give us reasons to revise our ethical beliefs iff we hold those beliefs due to their popularity was a view put forward in the 1980 s by Derek Parfit (1984). Parfit claimed that the discovery of an evolutionary explanation for some ethical belief is, in and of itself, no reason to revise our view. However, evolutionary

\footnotetext{
${ }^{19}$ See McLoone (2013) for a suggested revision of the Negative View that avoids counterexamples of this kind. ${ }^{20}$ Ariew (1996, 1999), Samuels (2002, 2004), Sober (1998), Stich (1975).
} 
considerations may serve to undercut someone whose confidence in some ethical proposition hinges on the fact that everyone accepts it. Since the fact that everyone accepts the proposition can be explained by natural selection without reference to its truth or falsity, its popularity provides no evidence that the proposition is true, and thus should not serve as a basis for adopting the belief in question. ${ }^{21}$

It has been characteristic of the new breed of philosophers working on evolutionary debunking arguments to want to go beyond this claim. They want to say that if some evaluative belief has an evolutionary explanation, this fact is not of itself neutral with respect to the justificatory status of the belief in question. Thus, Kahane (2011) says of Parfit (1984) that he "makes it seems as if evolutionary explanations only undermine the epistemic significance of wide agreement. But this is too weak.” (110) Parfit (2011) has since changed his view and now accepts the Debunking Thesis. In light of our discussion, we may worry that this is a mistake.

The fact that innate beliefs are the least plausible candidates for debunking by reference to facts about natural selection creates its own problems for those who accept the Debunking Thesis. Proponents of the Debunking Thesis typically rely on claims about innateness to establish a presumptive case that certain elements of our moral psychology can be outfitted with evolutionary explanations. For example, a key component in Joyce's (2006) debunking argument is evidence that human children everywhere readily acquire the ability to distinguish between moral and conventional norms; ${ }^{22}$ Joyce treats this as evidence that moral concepts are innate. ${ }^{23}$ Kahane claims that evolutionary debunking arguments "commit us to claims about innateness - not necessarily of the evaluative beliefs themselves,

\footnotetext{
${ }^{21}$ For a similar view, see Singer (1981).

${ }^{22}$ See Nucci (2001), Turiel (1983, 2006).

${ }^{23}$ This contradicts the view of the developmental psychologists responsible for the research discussed by Joyce. See, in particular, Nucci (2001: 13)
} 
but of strong dispositions that push people in their direction." (112) If I am right, evidence of innateness is in fact one of the best means by which to guard a belief against being debunked by appeal to facts about past selection pressures.

This problem could be overcome, of course, if those who accept the Debunking Thesis gave up their focus on innate features of our moral psychology. They would be advised to do so in any case. There is no necessary connection between adaptation and innateness. Many innate traits, such as autistic spectrum disorder, are not adaptations. Similarly, many adaptations are not innate. Street (2006) claims that "for evolution by natural selection to take place with respect to a given trait, the trait in question must be genetically heritable." (118) This is not so. Selection occurs when the members of a population vary in ways that lead some to survive and reproduce at greater rates than others, provided that those traits which lead to increased reproductive success are reliably transmitted across generations. The exact mechanism by which favoured traits are transmitted is not specified by the definition of natural selection, and Darwin famously had a poor understanding of the mechanism of biological inheritance. Thus, traits which are transmitted across generations as a matter of social learning can in principle evolve by selection and constitute adaptations.

As this shows, there is no necessary distinction between evolution and culture. A trait that is selected for and constitutes an element of cultural inheritance will be an adaptation, but certainly not an innate trait. Notably, recent work on the evolution of social norms and prosocial behaviour in human groups emphasizes culture as integral to the evolution of morality. ${ }^{24}$

This movement is bound up with the renaissance in explanations appealing to

\footnotetext{
${ }^{24}$ See Bowles \& Gintis (2011), Henrich \& Henrich (2007), Richerson \& Boyd (2005), Sober \& Wilson (1998). More exactly, the emphasis is on gene-culture co-evolution, which involves reciprocal interactions between cultural and genetic inheritance, as in the acquisition of lactase persistence by dairying peoples in Europe and Africa.
} 
selection across groups as a significant force in the evolution of moral norms and associated behaviours. ${ }^{25}$ The importance of culture to group selection derives from the fact that selection requires variation. Group selection is strongest when variation across groups is high and variation within groups is low. One of the reasons that biologists have been prone to dismiss group selection as an evolutionary force is that stable genetic differences between animal groups are typically slight and easily offset by migration and exogamy. ${ }^{26}$ When we introduce culture into our picture, this problem lessens. A system of cultural inheritance can render members of the same group more similar in their behaviour than their genetic commonalities would suggest and amplify the behavioural differences between genetically similar groups. The ability of cultural systems to suppress intragroup differences derives from the fact that acquisition of cultural traits is often sensitive to their prior distribution within the population. In particular, cultural transmission is governed by a conformist bias: individuals tend to imitate the most common behaviour observed within the population. ${ }^{27}$ Conformist bias helps renders cultural traits stable against the force of migration, with new arrivals tending to adopt the behaviour of the majority.

Emphasizing the role of culture in human evolution has thus allowed contemporary researchers to resurrect Darwin's (1879/2004) original suggestion that morality has evolved under natural selection "although a high standard of morality gives but a slight or no advantage to each individual man" since "an advancement in the standard of morality and an increase in the number of well-endowed men will certainly give an immense advantage to one tribe over another." (157-158) Contemporary research on cultural group selection appears to have gone largely unnoticed by moral philosophers who work on evolutionary debunking arguments. They now have an added reason to take notice. As I've

\footnotetext{
${ }^{25}$ On which, see Wilson \& Wilson (2007).

${ }^{26}$ See Maynard Smith (1964), Williams (1966).

${ }^{27}$ Henrich \& Boyd (1998).
} 
argued, traits whose acquisition depends on their prior distribution within the population seem the best candidates when it comes to the potential of selection to explain the traits of individuals. Beliefs and behaviours that we acquire from others as a matter of cultural transmission, in turn, are arguably the best candidates for traits of that kind. Thus, evolutionary debunking arguments that emphasize the role of truth-indifferent selection pressures would seem to be most likely to succeed when focused on moral beliefs that represent elements of cultural inheritance.

The picture at which we have ended up here is very different from the position typically advanced by those who endorse evolutionary debunking arguments in ethics. We have arrived at a position where innateness provides the best defence against the kind of debunking arguments with which we are familiar, since innate traits are least likely to be explained by selection. This is a surprising and counterintuitive result, especially given the emphasis on innateness that has characterised discussion of these arguments. It may seem too counterintuitive that innateness should have any kind of protective quality such as this. We might think it wise, therefore, to consider whether there is some way to preserve the idea that evolutionary considerations can play a role in providing undercutting defeaters for certain of our moral beliefs without doing such violence to our expectations.

\section{Doing without the Debunking Thesis}

An alternative response to the clash between the Debunking Thesis and the Negative View would be to explore whether the evolutionary debunking arguments currently available can be made to work even if we give up any suggestion that facts about natural selection explain why we believe what we do about right and wrong.

Consider Street's argument. Street claims that it would have to have been an extraordinary coincidence if the basic evaluative tendencies favoured by selection tend in the direction of the truth, given that there has been no selection for truth-conducive 
evaluative dispositions. More exactly, she claims that this would have to have been an extraordinary coincidence if the evaluative truths are mind-independent. We cannot reasonably expect that such a coincidence has occurred, she maintains. Thus, we acquire a defeater for any ethical belief underwritten by an evaluative disposition that has evolved by selection, unless we revise our meta-ethical view so as to reject ethical realism.

Central to Street's argument is the supposed implausibility of believing that natural selection has coincidentally favoured the evolution of objectively true moral beliefs. Any coincidence here involves facts about selection pressures and facts about what morality objectively requires. It might appear, then, that questions about the ability of selection to explain what we believe are superfluous. Whether the relevant selection pressures are assumed to explain our beliefs would arguably do nothing to make the coincidence between what was selectively advantageous and what was objectively true to believe any less extraordinary. Therefore, one might think, we cannot reasonably suppose that such a coincidence has occurred, regardless of what we believe about the capacity of selection to explain our moral beliefs. Sketched in these terms, any conflict between Street's argument and the Negative View may seem merely apparent.

I believe that the conflict is more than merely apparent. I grant that our stand on the Negative View does nothing to mitigate our sense of surprise at the suggestion that although selection has favoured various moral beliefs without regard to their truth or falsity, these nonetheless reliably happen to be (objectively) true. However, it seems to me more difficult to sustain the claim that we cannot reasonably believe that such a coincidence occurred if we also assume that the relevant selection pressures do not explain why we believe what we do about right and wrong.

There is, after all, no general ban on believing in very surprising coincidences, provided that we have some evidence for their occurrence. For example, there are uncanny resemblances between the sinking of the RMS Titanic in 1912 and a fictional ship-wreck 
described in Morgan Robertson's 1898 novella The Wreck of the Titan. Robertson's Titan is an ocean liner that strikes an iceberg on an April night, moving at 25 knots, and sinks 400 nautical miles from the coast of Newfoundland. The Titanic struck an iceberg on April $14^{\text {th }}$, moving 22.5 knots, and sank 400 nautical miles from Newfoundland. These coincidences are astonishing, but I don't think you would be unwarranted in accepting my testimony that they are real. ${ }^{28}$

Consider, then, the case of natural selection and moral facts. Unless she means to beg the question against the realist, Street must grant the assumption that we are ex ante justified in treating various moral propositions as objectively true. Information about the evolution of morality is then supposed to cancel out this justification. By learning about the selection pressures relevant to the evolution of morality, we are supposed to gain evidence that it would have required an improbable coincidence if the moral propositions whose acceptance was favoured by selection turn out also to be the moral propositions that are true as a matter of objective fact. Why should we then not conclude that such an improbable coincidence occurred? We start off justified in accepting that certain propositions are objectively true and then acquire evidence that natural selection favoured beliefs with those contents, albeit for reasons unconnected from their truth. Why is the proper response here not to combine these pieces of information and conclude that an astonishing coincidence occurred? 29

It is natural to feel that this move is unacceptable insofar as we think that the beliefs that have evolved by selection are our own. If we suppose that our beliefs are themselves the products of selection, then it may appear misguided to rely on these beliefs to certify that selection - against all odds - favoured the evolution of true moral beliefs. Consider an analogy: it seems obviously misguided to try to quell our suspicions about the reliability of

\footnotetext{
${ }^{28}$ I omit any supporting references to help test your intuitions on this point.

${ }^{29}$ For further development of this line of response to Street, see Setiya (2012).
} 
a witness by asking the witness whether she is reliable. ${ }^{30}$ Just as we cannot rely on her testimony to overturn our doubts about the reliability of the witness, so we might think we cannot rely on beliefs and intuitions about morality that arise from natural selection to quell any doubts about whether selection happened to reliably pick out objectively true moral beliefs. Street (2008) offers more or less exactly this reply in response to an argument by David Copp (2008).

The reasoning sketched in the previous paragraph requires, however, that our moral beliefs result from selection. If they do not, the charge of bootstrapping appears difficult to sustain. There is nothing untoward, after all, in certifying the reliability of a process by reference to some independent criterion. For example, I can rely on my perceptual experiences to verify that yours are reliable: I can check that you are not hallucinating by asking if you see the table that I see and the books I see and so forth. Similarly, we might think that there should be nothing untoward in relying on our ex ante justified moral beliefs to verify the reliability of selection if our moral beliefs are not the product of selection. Thus, a conflict with the Negative View appears to emerge after all. The charge that we cannot reasonably suppose that a coincidence of the requisite kind occurred does not appear to hold up unless the coincidence involves selection pressures that also explain why we believe what we believe about right and wrong.

Here is a different proposal for how we might redraft the debunking arguments currently on offer so as to beg no questions against the Negative View. Granting that selection doesn't explain our moral beliefs, there must nonetheless be some explanation for

\footnotetext{
30 Some philosophers (e.g., Bergmann 2006, Pryor 2004), believe it can be permissible to use bootstrapping reasoning to certify the reliability of a given method of belief-formation provided one has no antecedent reason to doubt the reliability of the method. So far as I am aware, no one defends the view that bootstrapping reasoning is acceptable in a case like that described here. Thus, Bergmann says: "You can't sensibly come to trust a doubted witness on the basis of that very witness's testimony on his own behalf.” (180)
} 
why we believe what we do about right and wrong: an explanation in terms of inheritance, development, and other proximate factors. We might suppose that the debunking arguments currently available can be refashioned so as to appeal instead to explanatory factors of this kind. In this vein, Street (2006) claims that the challenge posed by facts about natural selection "is not distinctly Darwinian” (155). Any explanation of our evaluative judgments will generate the same kind of problem, she claims, since any sufficiently complete explanation of our moral judgments will fail to accord explanatory significance to facts about right and wrong.

In discussion, I have been surprised at how often this point is raised as an objection against my argument. I am happy to concede that if we look beyond natural selection we may be able to construct debunking explanations that require us to revise some or all our moral beliefs. I outline a promising explanation of that kind in the next section.

At the same time, I don't believe we can simply assume that any adequate explanation will be debunking, as Street does. This assumption begs the question against the large number of philosophers who argue (with considerable skill) that moral facts can figure in the explanation of our moral beliefs. ${ }^{31}$

To show that there exists a cogent debunking argument targeting some or all of our moral beliefs, I believe we have to get our hands dirty and describe a discrediting explanation in concrete detail. Whether that explanation turns out to be debunking in light of the kind of epistemic principles that figure in familiar evolutionary debunking arguments is also, I believe, an open question: one that has be to be decided by looking at the particulars - and by independent assessment of the plausibility of these epistemic

\footnotetext{
${ }^{31}$ For example, Brink (1989), Cuneo (2006), Majors (2003), Oddie (2005), Sturgeon (1985, 1986, 2006), Wedgwood (2007), Wright (1992).
} 
principles. ${ }^{32}$

\section{Another way: explanation by phylogeny}

I believe we can retain our commitment to the idea that evolutionary considerations can debunk our moral beliefs, though we should give up the claim that these considerations have to do with natural selection. This section will offer some cursory suggestions as to how we might proceed along this path.

Natural selection is obviously not the only factor to which we can appeal in explaining evolutionary patterns of change and stability. Nor are those who accept the Debunking Thesis under any illusions about this. Kahane (2011) warns against assuming that debunking arguments must presuppose any form of strong adaptationism. ${ }^{33}$ If certain moral beliefs are explained not by selection but by other evolutionary processes, this, he claims, is grist to the debunker's mill: "If some evaluative disposition is explained not by adaptation but by the even more random evolutionary mechanisms of genetic drift or exaptation, this would make things worse, not better" (111-112). However, neither drift nor exaptation will help to avoid our problem concerning the explanatory scope of selection. Exaptation is just a special case of adaptation. Drift merely involves differential reproductive success that fails to track underlying differences in fitness, and so cannot plausibly explain anything that could not in principle be explained by adaptation: if we are worried about our ability to explain the moral beliefs of contemporary human beings by reference to non-random differential survival and reproduction, adding an element of randomness will surely do nothing to help.

There exists a different kind of evolutionary explanation that has greater promise as

\footnotetext{
${ }^{32}$ For an argument that familiar evolutionary debunking arguments rest on bad epistemology, see White (2010)

${ }^{33}$ See also Street (2006: 113-114).
} 
a basis for debunking arguments. What I have in mind is an explanation in terms of phylogeny or phylogenetic inheritance. Explanations in terms of phylogeny are essentially explanations by inheritance 'writ large': one seeks to explain the traits of organisms by adverting to their evolutionary inheritance, by placing them on the so-called 'tree of life'. So far as I am aware, there is no one who challenges the capacity of inheritance to explain the traits of individuals, and so there should be no one who challenges the view that considerations of phylogeny can explain the traits of individuals.

Here is my favourite example of this kind of explanation, which I borrow from Stephen Jay Gould (1994). Consider the horizontal tail-flukes of whales. These are, in one respect, an obvious adaptation for swimming. But why have whales evolved flukes that are horizontal, and not vertical, like the caudal fins of fish? It is implausible that whales inhabit special ocean environments in which horizontal flukes confer some advantage over the vertical alternative. The answer lies instead in cetacean phylogeny. Whales are descended from terrestrial mammals in the Artiodactyla order that ran on land by flexing their spinal columns in the vertical plane. When the ancestors of whales returned to the seas, their inherited body-plan necessitated the evolution of horizontal flukes that could be waved up and down to propel the animal forward. Thus, constraints imposed by phylogenetic inheritance explain the horizontal tails of whales.

It is not implausible that certain elements of human morality are like this. In fact, we appear to find this suggestion in the very first publication to address the evolutionary origins of morality from a Darwinian perspective: Darwin's Descent of Man. In seeking to explain the "moral sense" as arising through the gradual modification under natural selection of traits shared with other species, Darwin (1879/2004) posits that "any animal whatever, endowed with well-marked social instincts, would inevitably acquire a moral sense or conscience, as soon as its intellectual powers had become as well developed, or nearly as well developed, as in man.” (120-121) He claims that the social instincts which undergird 
the moral sense are "retained from an extremely remote period" (132) having originated with our "early ape-like progenitors." (133) ${ }^{34}$ Since the moral sense is founded on inherited social instincts, we should not expect, Darwin claims, that any social animal whose intellectual faculties are similar to those of human beings would acquire exactly the same moral beliefs. Like the orientation of the tail fin in aquatic vertebrates, the moral outlook of an organism will reflect idiosyncrasies of its phylogeny. "If, for instance, ... men were reared under precisely the same conditions as hive-bees, there can hardly be a doubt that our unmarried females would, like the worker-bees, think it a sacred duty to kill their brothers, and mothers would strive to kill their fertile daughters; and no one would think of interfering." (122)

Suggestions of this kind do not die with Darwin. In the same vein, Michael Ruse and E. O. Wilson (1986) claim that "ethical premises are the peculiar products of genetic history" (186). It is difficult to avoid the sense that claims of this kind challenge our moral beliefs, and certainly if we mean to claim objective truth for these beliefs. The challenge here seems analogous to another problem-issue that has gained prominence in contemporary philosophy. I have in mind the argument of Jonathan Weinberg, Shaun Nichols, and Stephen Stich that analytic philosophers' intuitions about knowledge are culturally parochial, reflecting arbitrary facets of Western social organization and/or social identity, in turn reflecting long-run historical differences in the economic means of subsistence. ${ }^{35}$ The results obtained by Weinberg et al. seem to challenge our epistemic intuitions in just the way that evidence of phyletic contingency challenges our moral intuitions.

In any case, evidence of this kind appears to offer a route by which to build debunking arguments that beg no questions against the Negative View. Such arguments

\footnotetext{
${ }^{34}$ For recent supporting evidence, see de Waal $(1996,2006)$.

35 Weinberg et al. (2001).
} 
would emphasize contingencies of phylogeny rather than selection as the problematic explanatory factors in evolutionary accounts of morality. As such, they could not plausibly be accused of resting on mistaken assumptions about the explanatory scope of selection.

\section{Conclusion}

I have argued that those who accept the Debunking Thesis beg important questions in the philosophy of biology. If we do not wish to give up altogether on the idea that evolutionary considerations can provide reasons for us to revise our moral beliefs - including any innate moral beliefs - the best response is to give up the emphasis on selection that has characterized recent debates. Instead, we should attempt to build debunking arguments that focus on the role of phylogenetic inheritance in explaining our moral outlook. Whether debunking arguments that emphasize the discrediting influence of phyletic contingencies are ultimately successful is an open question. ${ }^{36}$ In that respect, however, they appear better off than the debunking arguments proposed so far.

\section{Bibliography}

Ariew, Andrew (1996) Innateness and canalization. Philosophy of Science 63, S19-S27.

(1999) Innateness is canalization: In defense of a developmental account of innateness. In Valerie Gray Hardcastle, ed. (1999) Where biology meets Psychology: philosophical essays, 117-138. Cambridge, MA: MIT Press.

Bergmann, Michael (2006) Justification without awareness: a defense of epistemic externalism. Oxford: Oxford University Press.

Birch, Jonathan (2012) The Negative View of natural selection. Studies in History and Philosophy of Science Part C 43, 569-573.

Bowles, Samuel \& Gintis, Herbert (2011) A cooperative species: human reciprocity and its evolution. Princeton, NJ: Princeton University Press.

${ }^{36}$ See Mogensen (2014) for a detailed development of this kind of argument. 
Brink, David (1989) Moral realism and the foundations of ethics. Cambridge: Cambridge University Press.

Copp, David (2008) (2008) Darwinian skepticism about moral realism. Philosophical Issues 18, 186206.

Crisp, Roger (2006) Reasons and the good. Oxford: Oxford University Press.

Cummins, Robert (1975) Functional analysis. Journal of Philosophy 72, 741-765.

Cuneo, Terence (2006) Moral facts as configuring causes. Pacific Philosophical Quarterly 87, 141-162.

Darwin, Charles (1879/2004) The descent of man, and selection in relation to sex, $2^{\text {nd }}$ ed. London: Penguin

Dawkins, Richard (1986) The blind watchmaker. London: Penguin.

de Lazari-Radek, Katarzyna and Singer, Peter (2012) The objectivity of ethics and the unity of practical reason. Ethics 123, 9-31.

de Waal, Frans B. M. (1996) Good natured: the origins of right and wrong in humans and other animals. Cambridge, MA: Harvard University Press.

(2006) Primates and philosophers: how morality evolved. Princeton, NJ: Princeton University Press.

Forber, Patrick (2005) On the explanatory roles of natural selection. Biology and Philosophy 20, 329342.

Gibbard, Alan (1990) Wise choices, apt feelings: a theory of normative judgment. Cambridge, MA: Harvard University Press.

Gould, Stephen Jay (1994) Hooking Leviathan by its past. In his (2011) Dinosaur in a haystack: reflections in natural history, 359-376. Cambridge, MA: Harvard University Press.

Helgeson, Casey (2013) What selection can and cannot explain: a reply to Nanay's critique of Sober. Philosophy of Science 80, 155-159.

Henrich, Joseph \& Boyd, Robert (1998) The evolution of conformist transmission and the emerge of between-group differences. Evolution and Human Behavior 19, $214-241$.

Henrich, Natalie \& Henrich, Joseph (2007) Why humans cooperate: a cultural and evolutionary explanation. Oxford: Oxford University Press.

Huemer, Michael (2008) (2008) Revisionary intuitionism. Social Philosophy and Policy 25, 368-392. 
Joyce, Richard (2000) Darwinian ethics and error. Biology and Philosophy 15, 713-732.

(2001) The myth of morality. Cambridge: Cambridge University Press.

(2006) The evolution of morality. Cambridge, MA: MIT Press.

(forthcoming) Evolution, truth-tracking, and moral skepticism. In Bastian Reichardt, ed. Problems of goodness: new essays in metaethics.

Kahane, Guy (2011) Evolutionary debunking arguments. Nô̂s 45, 103-125.

Kripke, Saul (1981) Naming and necessity. Oxford: Blackwell.

Lewens, Tim (2001) Sex and selection: a reply to Matthen. British Journal of the Philosophy of Science $52,589-598$.

Majors, Brad (2003) Moral explanations and the special sciences. Philosophical Studies 113, 121-152.

Martinez, Maximiliano \& Moya, Andres (2011) Natural selection and multi-level causation.

Philosophy \& Theory in Biology 3, 1 - 14.

Matthen, Mohan (1999) Evolution, Wisconsin style: selection and the explanation of individual traits. British Journal of the Philosophy of Science 50, 143-150.

(2002) Is sex really necessary? And other questions for Lewens. British Journal of the Philosophy of Science 54, 287-308.

(2004) Origins are not essences in evolutionary systematics. Canadian Journal of Philosophy 32, $167-182$

Maynard-Smith, John (1964) Group selection and kin selection. Nature 201, 1145-7.

McLoone, Brian (2013) Selection explanations of token traits. Studies in History and Philosophy of Biology and Biomedical Science 44, 342-346.

Mogensen, Andreas (2014) Evolutionary debunking arguments in ethics. D. Phil. thesis. University of Oxford.

Nanay, Bence (2005) Can cumulative selection explain adaptation? Philosophy of Science 72, 10991112.

(2010) Natural selection and the limitations of environmental resources. Studies in History and Philosophy of Biological and Biomedical Sciences 41, 418-419.

Neander, Karen (1988) What does natural selection explain? Correction to Sober. Philosophy of 
Science 55, 422-426.

(1995a) Pruning the tree of life. British Journal of the Philosophy of Science 46, 59-80.

(1995b) Explaining complex adaptations: a reply to Sober's 'reply to Neander'. British Journal of the Philosophy of Science 46, 583-587.

Nozick, Robert (1981) Philosophical explanations. Cambridge, MA: Harvard University Press.

Nucci, Larry P. (2001) Education in the moral domain. Cambridge, Cambridge University Press.

Oddie, Graham (2005) Value, reality, and desire. Oxford: Oxford University Press.

Parfit, Derek (1984) Reasons and persons. Oxford: Oxford University Press.

(2011) On what matters, vol. 2. Oxford: Oxford University Press.

Pollock, John L. (1970) The structure of epistemic justification. American Philosophical Quarterly 4, $62-78$.

(1986) Contemporary theories of knowledge. Oxford: Rowman \& Littlefield.

Pryor, Jim (2004) What's wrong with Moore’s argument? Philosophical Issues 14, 349-377.

Pust, Joel (2001) Natural selection explanation and origins essentialism. Canadian Journal of Philosophy 31, 201-220.

(2004) Natural selection and the traits of individual organisms. Biology and Philosophy 19, 765779.

Razeto-Barry, Pablo \& Frick, Ramiro (2011) Probabilistic causation and the explanatory role of natural selection. Studies in History and Philosophy of Biology and Biomedical Sciences 42, 344-355.

Richerson, Peter J. \& Boyd, Robert (2005) Not by genes alone: how culture transformed human evolution. Chicago, IL: University of Chicago Press.

Rosenberg, Alex (2011) The atheist's guide to reality: enjoying life without illusions. New York: W. W. Norton \& Co.

Ruse, Michael (1986) Taking Darwin seriously: a naturalistic approach to philosophy. Oxford: Blackwell.

Ruse, Michael \& Wilson, E. O. (1986) Moral philosophy as applied science. Philosophy 61, 173-192.

Samuels, Richard (2002) Nativism in cognitive science. Mind and Language 17, 233-265.

(2004) Innateness in cognitive science. Trends in Cognitive Science 8, 136-141.

Setiya, Kieron (2012) Knowing right from wrong. Oxford: Oxford University Press. 
Singer, Peter (1981) The expanding circle: ethics and sociobiology. Oxford: Clarendon Press.

(2005) Ethics and intuitions. Journal of Ethics 9, 331 - 352.

(2006) Review: Richard Joyce, The evolution of morality. Notre Dame Philosophical Reviews. Last accessed 24.10.2013: <http://ndpr.nd.edu/news/25012/?id=6383>.

Sober, Elliott (1984) The nature of selection: evolutionary theory in philosophical focus. Cambridge, MA: MIT Press.

(1995) Natural selection and distributive explanation: a reply to Neander. British Journal of the Philosophy of Science 46, 384-397.

(1998) Innate knowledge. In Edward Craig, ed. (1998) Routledge Encyclopedia of Philosophy. Last accessed 13/12/2011: <http://www.rep.routledge.com/article/P027.>

Sober, Elliott \& Wilson, David Sloan (1998) Unto others: the evolution and psychology of unselfish behavior. Cambridge, MA: Harvard University Press.

Stegmann, Ulrich E. (2010a) What can natural selection explain? Studies in History and Philosophy of Science Part C: Studies in History and Philosophy of Biological and Biomedical Sciences 41, 61-66.

(2010b) Reply to Bence Nanay's 'Natuarl selection and the limited nature of environmental resources'. Studies in History and Philosophy of Biological and Biomedical Sciences 41, 418-419.

Stich, Stephen (1975) Introduction. In Stephen Stich, ed. Innate Ideas, 1 -22. Berkeley, CA: University of California Press.

Street, Sharon (2006) A Darwinian dilemma for realist theories of value. Philosophical Studies 127, 109-166.

(2008) Reply to Copp: naturalism, normativity, and the varieties of realism worth worrying about. Philosophical Issues 18, 207-228.

(2011) Mind-independence without mystery: why quasi-realists can't have it both ways. In Russ Shafer-Landau, ed. (2011) Oxford studies in meta-ethics, vol. 6, 1-32. Oxford: Oxford University Press.

Strevens, Michael (2008) Depth: an account of scientific explanation. Cambridge, MA: Harvard University Press.

Sturgeon, Nicholas L. (1985) Moral explanations. In Geoffrey Sayre-McCord, ed. (1988) Essays on 
moral realism, 229-255. Ithaca, NY: Cornell University Press.

(1986) Harman on moral explanations of natural facts. Southern Journal of Philosophy 24, suppl. $43-55$.

(2006) Moral explanations defended. In James Dreier, ed. (2006) Contemporary debates in moral theory, 241-262. Oxford: Blackwell.

Turiel, Elliott (1983) The development of social knowledge: morality \& convention. Cambridge: Cambridge, University Press.

(2006) The development of morality. In William Damon, Richard M. Lerner, \& Nancy Eisenberg, eds. (2006). Handbook of child psychology, $6^{\text {h }}$ ed., vol. 3: social, emotional, and personality development, 789-857. Hoboken, NJ: John Wiley \& Sons.

Walsh, Denis M. (1998) The scope of selection: Sober and Neander on what natural selection explains. Australasian Journal of Philosophy 76, 250-264.

Walsh, Denis M., Tim Lewens, \& Andrew Ariew (2002) Natural selection and random drift. Philosophy of Science 69, 452-473.

Wedgwood, Ralph (2007) The nature of normativity. Oxford: Oxford University Press.

Weinberg, Jonathan M., Shaun Nichols, \& Stephen Stich (2001) Normativity and epistemic intuitions. Philosophical Topics 29, 429-460.

White, Roger (2010) You just believe that because... Philosophical Perspectives 24, 573-615.

Williams, George C. (1966) Adaptation and natural selection: a critique of some current evolutionary thought. Princeton, NJ: Princeton University Press.

Wilson, David Sloan \& Wilson, Edward O. (2007) Rethinking the theoretical foundations of sociobiology. The Quarterly Review of Biology 82, 327-348.

Wright, Crispin (1992) Truth and objectivity. Cambridge, MA: Harvard University Press. 